\title{
ASPECTOS DE RESPONSABILIDADE AMBIENTAL NA FOMENTAÇÃO DA SUSTENTABILIDADE NO MUNICÍPIO DE PINHEIROS (ES)
}

\author{
Ivanete Batista Martins ${ }^{1}$ \\ Vivian Hannah Mota de Andrade ${ }^{2}$ \\ Aline Pinheiro Lima Camargo ${ }^{3}$
}

Resumo: O presente estudo visa apresentar os fomentadores da sustentabilidade no município de Pinheiros, na região norte do estado do Espírito Santo, sob o fundamento da Educação Ambiental. A análise e interpretação dos dados coletados em aulas de campo pelos alunos do curso de Mestrado em Ciência, Tecnologia e Educação da Faculdade Vale do Cricaré mostraram o seguinte resultado: A Associação de Materiais Recicláveis e uma empresa produtora de café estão contribuindo para sustentabilidade, no entanto, a representação da sustentabilidade, a Reserva Biológica Córrego do Veado está ameaçada de extinção por falta de efetivas políticas do poder público federal para garantir o direito à proteção integral.

Palavras-chave: Reserva Biológica; Sustentabilidade; Gestão Pública; Pinheiros.

Abstract: This study aims to present the sustainability promoters in the municipality of Pinheiros, in the northern region of the state of Espírito Santo (Brazil), under the foundation of Environmental Education. The analysis and interpretation of data collected in field classes by students of the Master's course in Science, Technology and Education at Faculdade Vale do Cricaré showed the following result: The Association of Recyclable Materials and a coffee producing company are contributing to sustainability, in the However, the representation of sustainability, the Córrego do Veado Biological Reserve is threatened with extinction due to the lack of effective policies of the federal public power to guarantee the right to full protection.

Keywords: Biological Reserve; Sustainability; Public Management; Pinheiros.

${ }^{1}$ Faculdade Vale do Cricaré. E-mail: ivanete.jus@gmail.com.

Link para o Lattes: http://lattes.cnpq.br/8454062953457921

${ }^{2}$ Faculdade Vale do Cricaré. E-mail: vivian.hannah18@gmail.com.

Link para o Lattes: http://lattes.cnpq.br/8390193682281860

${ }^{3}$ Faculdade Vale do Cricaré. E-mail: profalinelimacamargo@gmail.com.

Link para o Lattes: http://lattes.cnpq.br/9351766283520706

Revbea, São Paulo, V. 17, № 1: 335-349, 2022.

revista brasileira 


\section{Introdução}

Este artigo propõe mostrar a responsabilidade dos fomentadores da sustentabilidade no município de Pinheiros e região norte do estado do Espírito Santo, evidenciando os aspectos positivos do setor público e privado na preservação do meio ambiente. Os atores principais são: A Associação dos Catadores de Materiais Recicláveis do Município de Pinheiros/ES (ASCAP), que implantou a coleta seletiva do lixo urbano e doméstico para reciclagem; uma empresa do ramo de café que utiliza inovação tecnológica para secagem do café, na qual observa-se a preocupação dos seus gestores em não desmatar, e sim preservar as árvores e o solo, preocupam-se ainda em minimizar as partículas de fumaças emitidas no ar; e, por fim, a Reserva Biológica (Rebio) Córrego do Veado, floresta da Mata Atlântica de proteção integral da flora e da fauna. Percebe-se uma intrínseca relação entre a educação ambiental e a responsabilidade sustentável do setor privado, no entanto, observa-se que o poder público não tem garantido essa proteção.

Outrora, o município de Pinheiros/ES celebrou Termo de Referência que teve por objetivo a contratação da ASCAP, para prestação de serviços de coleta de lixo porta a porta ou nos pontos de entrega voluntária, para cumprir o acordo firmado no ano de 2013 com o poder Ministério Público do Estado do Espírito Santo. A coleta seletiva de materiais recicláveis possui capacidade de influir de maneira positiva no bem-estar social, na geração de emprego e na promoção social dos associados da ASCAP.

Já a empresa produtora de café vem se destacando no referido município por promover a educação ambiental, e proporcionar sustentabilidade no supracitado município. O destaque principal é a implantação do processo de secagem de café indireto, utilizando resíduos proveniente da pilagem (casca ou palha) do café para queima, produção de calor que induz a secagem dos grãos e todo esse processo visa contribuir para a preservação do meio ambiente.

Ademais, a Reserva Biológica Córrego do Veado (Rebio) é uma instância federal do grupo de proteção integral, e está sob a Jurisdição Legal de Domínio Mata Atlântica, também localizada no município de Pinheiros/ES. Observa-se que a sua criação possui como premissa a preservação da fauna e da flora. Outrora, a Rebio abrigou diversidade de espécies animais ameaçados de extinção como: a preguiça-de-coleira, o gavião-real, a cotinga, o macuco e alguns raros beija-flores, infelizmente esses estão em extinção e a floresta está enfrentando um problema de seca permanente.

Diante desse fato, entende-se que a responsabilidade na manutenção da sustentabilidade da referida floresta é do poder público federal, contudo, observa-se que a floresta está em situação periclitante: durante a visita técnica, notou-se que esse espaço nativo está desprovido de água, o motivo está na construção de represas pelos fazendeiros que a interceptam, antes que a mesma possa chegar à floresta, esse é um dos fatores que leva a região à situação de seca permanente, inviabilizando a proteção de mata nativa, o que 
provoca enxurradas em casos de chuvas muito fortes e, posteriormente, o retorno da seca. Essa ação poderá resultar na extinção de algumas espécies de plantas e na sobrevivência dos animais da floresta, situação que coloca em colisão direitos e preceitos fundamentais garantidos pela República Federativa do Brasil do ano de 1988.

Em relação ao enquadramento metodológico do referido estudo, a investigação caracteriza-se por meio de pesquisa exploratória sobre a proteção ambiental do Poder Público Federal e o Setor Privado no município de Pinheiros, no Estado do Espírito Santo. A realização das aulas de campo da disciplina de Educação e Tecnologia Ambiental da Pós-Graduação Stricto Sensu do curso de Mestrado em Ciência, Tecnologia e Educação da Faculdade Vale do Cricaré oportunizou esta observação. A presente pesquisa apresentase dentro do método qualitativo ao tipo de pesquisa bibliográfica e a ferramenta de busca foi a internet.

\section{Aspectos legais da gestão dos resíduos sólidos}

A priori extrai-se que o Decreto Federal $n \div 07.404 / 2010$ regulamentou a Lei Federal no 12.305/2010 para instituir a Política Nacional de Resíduos Sólidos (PNRS). Ambos os instrumentos legais norteiam a gestão e o gerenciamento de resíduos sólidos, pois indicam a forma de gestão desses resíduos para obtenção de níveis sustentáveis a toda a população. Observa-se que esse processo compreende o dever de adotar mecanismos para participação da sociedade. Entende-se que na estruturação de sistema de coleta seletiva, em parceria com as organizações de catadores, não foram observados pela administração pública do município de Pinheiros/ES as políticas públicas setoriais.

Nesse sentido, verificou-se que o Ministério Público do Estado do Espírito Santo e o Ministério Público do Trabalho celebraram Termo de Compromisso Ambiental - TCA no 01/13 com o município de Pinheiros/ES a fim de que fossem adotadas as medidas para destinação e adequação de resíduos sólidos para respeitar a lei 12.305/2010. Ademais, entre as obrigações estabelecidas para 0 município, ficaram estabelecidas as seguintes disposições:

- promover a formalização de catadores de materiais recicláveis em associações/cooperativas;

- disponibilizar equipamentos e estrutura para as organizações de catadores, tais como galpão de armazenamento, prensas, balanças, picotadeiras e outros;

- destinar à organização ou às organizações dos catadores, por região em que atuam ou, excepcionalmente, por acordo entre elas, de forma gradativa, o resíduo urbano reciclável gerado no Município, coletado no programa de coleta seletiva, devendo o percentual ser discutido por ocasião da 
revisão do edital de contratação de prestação de serviço de coleta e destinação de resíduos sólidos.

A referida lei dispõe sobre seus princípios, objetivos e instrumentos, bem como sobre as diretrizes relativas à gestão integradas ao gerenciamento de resíduos sólidos, incluídos os perigosos, às responsabilidades dos geradores e do poder público e aos instrumentos econômicos aplicáveis.

Diante das informações, observa-se ainda que o artigo $5^{\circ}$ da Lei de Política Nacional do Meio Ambiente integra a Política Nacional de Educação Ambiental, além de regular a Lei no 9.795, de 27 de abril de 1999, em consonância com a Política Federal de Saneamento Básico, sendo ainda observada a lei ํㅜ 11.445, de 2007, Lei no 11.107, de 6 de abril de 2005, conforme a seguir:

Art. $5^{\circ}$ A Política Nacional de Resíduos Sólidos integra a Política Nacional do Meio Ambiente e articula-se com a Política Nacional de Educação Ambiental, regulada pela Lei n 9.795, de 27 de abril de 1999, com a Política Federal de Saneamento Básico, regulada pela Lei $\mathrm{n}^{\circ}$ 11.445, de 2007, e com a Lei $\mathrm{n}^{\circ}$ 11.107, de 6 de abril de 2005.

Considera-se para este momento que todas as normas supramencionadas na citação acima visam ratificar o artigo 225 da Constituição da República Federativa do Brasil na seguinte expressão:

Art. 225. Todos têm direito ao meio ambiente ecologicamente equilibrado, bem de uso comum do povo e essencial à sadia qualidade de vida, impondo-se ao Poder Público e à coletividade o dever de defendê-lo e preservá-lo para as presentes e futuras gerações.

As diretrizes aplicáveis aos resíduos sólidos na gestão e gerenciamento de resíduos sólidos estão previstas no artigo 9ำ da Lei devendo ser observadas a seguinte ordem de prioridade: não geração, redução, reutilização, reciclagem, tratamento dos resíduos sólidos e disposição final ambientalmente adequada dos rejeitos.

Observa-se que o capítulo $\mathrm{V}$, artigo 42 da já mencionada lei, revela que o poder público poderá instituir medidas indutoras e linhas de financiamento para atender, prioritariamente, às iniciativas de: 
I - prevenção e redução da geração de resíduos sólidos no processo produtivo;

II - desenvolvimento de produtos com menores impactos à saúde humana e à qualidade ambiental em seu ciclo de vida;

III - implantação de infraestrutura física e aquisição de equipamentos para cooperativas ou outras formas de associação de catadores de materiais reutilizáveis e recicláveis formadas por pessoas físicas de baixa renda;

IV - desenvolvimento de projetos de gestão dos resíduos sólidos de caráter intermunicipal;

V - estruturação de sistemas de coleta seletiva e de logística reversa;

VI - descontaminação de áreas contaminadas, incluindo as áreas órfãs;

VII - desenvolvimento de pesquisas voltadas para tecnologias limpas aplicáveis aos resíduos sólidos;

VIII - desenvolvimento de sistemas de gestão ambiental e empresarial voltados para a melhoria dos processos produtivos e ao reaproveitamento dos resíduos.

Nessa exposição, percebe-se que a Lei de Política Nacional de Resíduos Sólidos prevê ainda que a União, os Estados, o Distrito Federal e os Municípios, no âmbito de suas competências, poderão instituir normas com o objetivo de conceder incentivos fiscais, financeiros ou creditícios, respeitadas as limitações da Lei de Responsabilidade Fiscal a:

I - indústrias e entidades dedicadas à reutilização, ao tratamento e à reciclagem de resíduos sólidos produzidos no território nacional;

II - projetos relacionados à responsabilidade pelo ciclo de vida dos produtos, prioritariamente em parceria com cooperativas ou outras formas de associação de catadores de materiais reutilizáveis e recicláveis formadas por pessoas físicas de baixa renda;

III - empresas dedicadas à limpeza urbana e a atividades a elas relacionadas.

No entanto, são proibidos na forma da Lei:

I - lançamento em praias, no mar ou em quaisquer corpos hídricos:

II - lançamento in natura a céu aberto, excetuados os resíduos de mineração;

III - queima a céu aberto ou em recipientes, instalações e equipamentos não licenciados para essa finalidade;

IV - outras formas vedadas pelo poder público. 
$\S 10$ Quando decretada emergência sanitária, a queima de resíduos a céu aberto pode ser realizada, desde que autorizada e acompanhada pelos órgãos competentes do Sisnama, do SNVS e, quando couber, do Suasa.

§ 20 Assegurada a devida impermeabilização, as bacias de decantação de resíduos ou rejeitos industriais ou de mineração, devidamente licenciadas pelo órgão competente do Sisnama, não são consideradas corpos hídricos para efeitos do disposto no inciso I do caput.

O art. 48 aduz que são proibidas, nas áreas de disposição final de resíduos ou rejeitos, as seguintes atividades:

I - utilização dos rejeitos dispostos como alimentação;

II - catação;

III - criação de animais domésticos;

IV - fixação de habitações temporárias ou permanentes;

$\mathrm{V}$ - outras atividades vedadas pelo poder público.

Verifica-se que a lei proíbe a importação de resíduos sólidos perigosos e rejeitos, bem como de resíduos sólidos cujas características causem dano ao meio ambiente, à saúde pública e animal e à sanidade vegetal, ainda que para tratamento, reforma, reuso, reutilização ou recuperação.

\section{Da missão da Associação ASCAP}

O município de Pinheiros celebrou com o Ministério Público do Estado do Espírito Santo e o Ministério Público do Trabalho o Termo de Compromisso Ambiental - TCA no 01/13, a fim de que fossem adotadas as medidas destinadas a adequar a gestão municipal de resíduos sólidos à Lei da PNRS (Lei 12.305/2010). A legislação brasileira norteou a gestão e o gerenciamento de resíduos sólidos, indicando que a gestão de resíduos sólidos, para obtenção de níveis sustentáveis a toda a população, deve adotar mecanismos de participação da sociedade, incluindo a estruturação de sistema de coleta seletiva em parceria com as organizações de catadores, sem prejuízo da observância das políticas setoriais.

A Associação dos Catadores de Materiais Recicláveis do Município de Pinheiros/ES (ASCAP) foi contratada por meio de processo licitatório para a prestação de serviços de coleta de lixo seco porta a porta ou Ponto de Entrega Voluntária (PEV); operacionalização da Usina de Triagem e Compostagem (UTC) de Resíduos Sólidos Urbanos (RSU) e Domiciliares; Operacionalização de Aterro controlado de RSU localizado na UTC; Operacionalização da Unidade de Transbordo de Resíduos de Construção Civil (RCC) e do Pátio de galhagem, localizados próximo à UTC.

Os serviços de coleta e transporte de material passível de reciclagem são compostos pelo conjunto de ações voltadas ao recolhimento de materiais 
passíveis de reciclagem nas áreas abrangidas pelos sistemas de coleta seletiva.

No município de Pinheiros/ES, os modelos adotados são: coleta porta a porta, Pontos de Entrega Voluntária (Pivôs) e entrega voluntária em pontos determinados (ex.: supermercados, papelarias, lojas comerciais, entre outros). A execução dos serviços de coleta é feita de acordo com a implantação do Projeto Básico da Coleta Seletiva e orientação das Secretarias de Obras e Urbanismo e Agricultura e Meio Ambiente. A ASCAP disponibiliza veículo específico e coletadores para realizar os serviços de coleta nas rotas já existentes e as que ainda vierem a serem implantadas. Os resíduos coletados são destinados à Usina de Triagem e Compostagem (UTC) para serem triados.

A Associação de Catadores executa suas atividades em galpão cedido pela Prefeitura de Pinheiros para separação/triagem dos resíduos sólidos domésticos coletados, tanto o da coleta seletiva quanto o da coleta do caminhão compactador, visando a disponibilização do material passível de reciclagem no ciclo produtivo. Os resíduos são levados para a UTC, onde passam por um processo de triagem, classificação, enfardação e armazenamento para expedição (venda) adequadamente.

Percebeu-se ainda que 0 material reciclável enfardado fica condicionado/armazenado de forma compactada, na própria UTC, até o momento da sua venda. Verificou-se que a Prefeitura faz doação desse material reciclável para a ASCAP e os recursos arrecadados com a venda são usados para ações de educação ambiental e para manutenção da UTC, do Transbordo de RCC e Pátio de Galhagem.

Os Resíduos da Construção Civil (RCC) provenientes de construções, reformas, reparos e demolições de obras de construção civil, e os resultantes da preparação e da escavação de terrenos, tais como: tijolos, blocos cerâmicos, concreto em geral, solos, rochas, metais, resinas, colas, tintas, madeiras, compensados, forros, argamassa, gesso, telhas, pavimento asfáltico, vidros, plásticos, tubulações, fiação elétrica etc., comumente chamados de entulhos de obras ou caliça, esses são classificados em: Resíduos Classe A, Classe B, Classe C e Classe D. A Associação possui Licença Ambiental para o Transbordo de RCC e demolição. O transbordo está localizado próximo à UTC.

A Associação operacionaliza ainda o processo de compostagem, utilizando os resíduos originados do lixo úmido como restos de comida, cascas de frutas e verduras, entre outros; do material resultado de podas e corte de plantas, coletadas pela Prefeitura Municipal e destinadas ao pátio de galhagem. $O$ adubo produzido é cedido à Prefeitura de Pinheiros para ser utilizado nas atividades de jardinagem pública.

Desta forma, foi observado durante a visita técnica que a figura da Associação é fundamental para o município de Pinheiros/ES, considerando que a coleta seletiva do lixo doméstico é extremamente importante para o meio 
ambiente e serve como parâmetro para estabelecer a consciência ambiental, melhorando a condição de vida.

As disposições supracitadas referem-se ao Termo de Compromisso Ambiental 01/2013 celebrado entre o Ministério Público do Estado do Espírito Santo e o Município de Pinheiros para fazer gerir o programa de coleta seletiva, culminando na formalização da Associação dos Catadores de Materiais Recicláveis do Município de Pinheiros/ES.

Outrossim, no dia 26/10/2015 celebrou Termo de Referência para a contratação de coleta de lixo seco entre outros, a licitação teve por objetivo a contratação da Associação de catadores de materiais recicláveis do município de Pinheiros/ES, para a prestação de serviços de coleta de lixo porta a porta ou nos pontos de entrega voluntária, dentro desta proposta, verificou-se que a operacionalização seria a Usina de triagem e compostagem de resíduos sólidos urbanos e domiciliares, dentro do previsto controle do aterro controlado por resíduos sólidos urbanos e a operacionalização do transbordo dos resíduos da construção civil e do pátio de galhagem.

Verificou-se que o principal desafio da gestão de resíduos é a diminuição dos níveis de desperdício de materiais e de aterramento de resíduos. A coleta seletiva e a triagem dos materiais recicláveis, bem como a compostagem, gerados na etapa do pós-consumo de bens, produtos e serviços permitem a ampliação de oportunidades para geração de trabalho e renda; a estruturação e a consolidação da cadeia econômica da reciclagem, com reflexos positivos nos aspectos socioambientais; o fortalecimento de organizações sociais, permitindo a inclusão e a integração de novos componentes; a melhoria das condições de limpeza e de salubridade dos espaços públicos; a redução dos custos de gestão e de manejo de resíduos sólidos; e o melhor aproveitamento dos aterros sanitários, reduzindo os custos de manutenção e a consequente ampliação da vida útil dos mesmos.

A coleta seletiva de materiais recicláveis possui capacidade de influir, de maneira positiva, em vários setores da vida social e da administração municipal, ao ser instrumento de promoção de benefícios como os acima citados, o que justifica essa proposição.

Nota-se que a formalização da relação entre o titular da prestação de serviço com as organizações de catadores de material reciclável, prevista no conjunto de exigências da Política Nacional de Resíduos Sólidos, inclui a possibilidade da contratação dispensada de licitação, conforme instituiu dispositivo que trata da prestação dos serviços públicos de limpeza urbana e manejo de resíduos sólidos, presente na Lei Federal ํㅜ 11.445/2007 (Política Nacional de Saneamento) e no artigo 24, inciso XXVII da Lei Federal n.. 8.666/1993.

Diante do exposto, ficou evidente o interesse público e a necessidade da contratação da Associação dos Catadores de Materiais Recicláveis do 
Município de Pinheiros/ES para cumprir o acordo celebrado por meio do Termo de Compromisso Ambiental.

Em suma, depreende-se que para atingir a missão proposta prevista no Termo de Compromisso Ambiental em manter os níveis de sustentabilidade no município de Pinheiros/ES é necessária a realização de serviços, a seguir: a coleta e transporte de materiais passíveis de reciclagem, triagem do lixo, serviço de operacionalização do processo de compostagem (espécie de reciclagem do lixo orgânico adubo, que pode ser usado na agricultura ou em jardins e plantas), serviços de operacionalização do transbordo de resíduos da construção civil, serviços de operacionalização do pátio de galhagem, serviços de operacionalização do aterro Controlado, serviços de manutenção e Educação Ambiental.

\section{Do Sistema Nacional do Meio Ambiente}

A capacidade de atuação do Estado na área ambiental baseia-se na ideia de responsabilidades compartilhadas entre União, estados, Distrito Federal e municípios, além da relação desses com os diversos setores da sociedade. Essa concepção teve origem na Lei $n^{\circ} 6.938$, de 31 de agosto de 1981, que dispõe sobre a Política Nacional de Meio Ambiente. A Lei, além de estabelecer conceitos, princípios, objetivos, instrumentos, mecanismos de aplicação e de formulação, institui o Sistema Nacional do Meio Ambiente (SISNAMA).

O SISNAMA surgiu com a finalidade de estabelecer um conjunto articulado de órgãos, entidades, regras e práticas, responsáveis pela proteção e pela melhoria da qualidade ambiental. Os órgãos e entidades da União, dos estados, do Distrito Federal, e dos municípios, bem como as fundações instituídas pelo Poder Público, responsáveis pela proteção e melhoria da qualidade ambiental, constituem o Sistema Nacional do Meio Ambiente, estruturado por meio dos seguintes níveis político-administrativos:

Órgão superior: o Conselho de Governo, com a função de assessorar o Presidente da República na formulação da política nacional e nas diretrizes governamentais para o meio ambiente e os recursos ambientais.

Órgão consultivo e deliberativo: o Conselho Nacional do Meio Ambiente (CONAMA), com a finalidade de assessorar, estudar e propor ao Conselho de Governo, diretrizes de políticas governamentais para o meio ambiente e os recursos naturais; e deliberar, no âmbito de sua competência, sobre normas e padrões compatíveis com o meio ambiente ecologicamente equilibrado e essencial à sadia qualidade de vida. Reúne diferentes setores da sociedade e tem o caráter normativo dos instrumentos da política ambiental. O plenário do CONAMA engloba todos os setores do governo federal, dos governos estaduais, representantes de governos municipais e da sociedade, incluindo setor produtivo, empresarial, de trabalhadores e organizações não governamentais. 
Órgão central: ao Ministério do Meio Ambiente cabe a função de formular, planejar, coordenar, supervisionar e controlar a política nacional e as diretrizes governamentais para o meio ambiente.

Órgão executor: o Instituto Brasileiro do Meio Ambiente e dos Recursos Naturais Renováveis (IBAMA), com a finalidade de executar e fazer executar as políticas e diretrizes governamentais definidas para o meio ambiente.

Órgãos seccionais: os órgãos ou entidades da Administração Pública Federal direta ou indireta, as fundações instituídas pelo Poder Público cujas atividades estejam associadas à proteção da qualidade ambiental ou as de disciplinamento do uso dos recursos ambientais, bem como os órgãos e entidades estaduais responsáveis pela execução de programas e projetos e pelo controle e fiscalização de atividades capazes de provocar a degradação ambiental.

Órgãos locais: os órgãos ou entidades municipais, responsáveis pelo controle e fiscalização dessas atividades, nas suas respectivas jurisdições. Os estados, o Distrito Federal e os municípios, na esfera de suas competências e nas áreas de suas jurisdições, elaborarão normas supletivas e complementares, e padrões relacionados com o meio ambiente, observados os que forem estabelecidos pelo CONAMA.

Verifica-se que suas principais funções são:

- implementar a Política Nacional do Meio Ambiente;

- estabelecer um conjunto articulado de órgãos, entidades, regras e práticas responsáveis pela proteção e pela melhoria da qualidade ambiental;

- garantir a descentralização da gestão ambiental, através do compartilhamento entre os entes federados (União, Estados e Municípios).

O Ministério do Meio Ambiente publica que o referido Sistema foi instituído há 24 anos, e representou o começo da descentralização na gestão ambiental. Todavia, para atuar como um sistema, não basta ao SISNAMA um conjunto de órgãos e de instrumentos.

Segundo Antunes (2017), a Política Nacional do Meio Ambiente, define o meio ambiente como sendo patrimônio político a ser assegurado e protegido, considerando o seu uso pelo coletivo. Posteriormente, e persistindo na mesma concepção, a Constituição da República Federativa do Brasil definiu que o meio ambiente ostenta a condição de bem de uso comum do povo, o que, de certa forma, fortalece e reafirma a ideia de indisponibilidade do direito ao meio ambiente.

Entretanto, se faz necessário que se atente ao artigo 225 da Constituição Federal o qual admite, de forma clara, a possibilidade de recategorização das Unidades de Conservação, sendo alteração e a supressão permitida, o que somente ocorrerá através de lei. Revela que é desnecessário reafirmar que a hipótese tratada pela Norma Fundamental é aplicável quando categoria de Unidade de Conservação implicar nível menor de Proteção 
Ambiental. Exemplo: a hipótese de transformação de um parque em áreas de Proteção Ambiental, nesse caso, a Unidade de Conservação Ambiental, passa do grupo de proteção integral para o grupo de uso sustentável, o que implica grande parte da área cuja utilização. No regime de parque era indireta, no novo regime jurídico poderá sujeitar a utilização direta, ou seja, a lei autorizou que fossem alienadas parcelas de direito indisponível.

Antunes (2017) argui ainda que existe um caso concreto, exemplo: a lei 11.686, de 2 de junho de 2008, que transformou o Parque Nacional dos Pontões Capixaba, embora Unidades de Conservação pertença ao grupo de Proteção Integral, considerou que o artigo 225 da Constituição da República Federativa do ano de 1988, dada a condição de um dos direitos mais caro à coletividade, possui eficácia imediata, conforme o entendimento da corrente majoritária.

\section{Aspectos da Educação Ambiental}

A lei 9.795 , de 27 de abril do ano 2009, que dispõe sobre a educação ambiental no Brasil, institui política nacional de educação ambiental e possui o entendimento de que educação ambiental é os processos por meio dos quais o indivíduo e a coletividade constroem valores sociais, conhecimentos, habilidades, atitudes e competências voltadas para a conservação do meio ambiente, bem de uso comum do povo, essencial à sadia qualidade de vida e sua sustentabilidade.

Nesse entendimento, a legislação brasileira dispõe de dois tipos de educação ambiental: 1) a formal, aquela desenvolvida na escola no âmbito dos currículos das instituições de ensino públicas e privadas, englobando, a educação básica, educação infantil, ensino fundamental e ensino médio, ensino superior, educação especial, a educação profissional, e jovens adultos; 2) a não formal, consolidada em ações e práticas educativas voltadas à sensibilização da coletividade sobre as questões ambientais. Exemplo da educação ambiental não formal são as ações praticadas na maioria das vezes fora do ambiente escolar, buscando conscientizar sobre a importância da proteção e preservação do bem comum a todos, o meio ambiente.

Não é apenas o espaço escolar que pode contribuir como responsável pela sensibilização da sociedade para as questões ambientais. No Brasil e em diversos países do mundo, existem diversas experiências em que foram trabalhados temas referentes à Educação Ambiental que não aconteceram entre os muros da escola, mas sim em espaços mais amplos, como igrejas, parques ecológicos, organizações não-governamentais, associações de moradores, grupos de amigos, escoteiros, propriedades rurais e mesmo em espaços abertos, como o centro da cidade, ou seja, muitos espaços transformam-se em lócus de estudos e reflexões ambientais (OLIVEIRA et al., 2020, p. 11-12). 
Segundo Agrizzi et. al. (2020), é fundamental que as escolas e Unidades de Conservação fortaleçam parcerias, bem como realizem um planejamento de acordo com o projeto pedagógico da escola, não limitado apenas a ações pontuais. Pois, considera-se que a experiência com a natureza é importante para ressignificar a percepção acerca de questões ambientais.

Para Antunes (2017), a Constituição Federal elevou o meio ambiente à condição de direito de todos e bem de uso comum do povo, modificando o conceito jurídico de meio ambiente. Ainda segundo o autor, essa mudança justifica-se pela alta relevância do bem jurídico tutelado, a Lei fundamental estabeleceu a obrigação do poder público e da comunidade de preservá-lo para as presentes e futuras gerações, por essa razão, foram criadas situações distintas que culminaram em: não promover degradação e promover a recuperação de áreas já degradadas.

A Constituição Federal fez uma escolha clara pela conservação que, necessariamente, tem sido interpretada de maneira dinâmica. Criou ainda a obrigação de zelar para que o meio ambiente não se olvide, sobretudo, que o conceito de uso comum de todos rompe com o enfoque de que os bens de uso comum só podem ser bens públicos. $\mathrm{E}$ ainda estabeleceu que, mesmo sob a égide do domínio privado, podem ser fixadas obrigações para que os proprietários assegurem a fruição, por todos, dos aspectos de bens de sua propriedade quando o assunto é meio ambiente (ANTUNES, 2017).

\section{Visão sustentável e econômica de uma empresa produtora de café}

Uma empresa produtora de café no município de Pinheiros/ES é um grande exportador de café na região. Durante a visita técnica observou-se como é realizado o processo de secagem de café indireto, utilizando resíduos provenientes da pilagem (casca ou palha) do café para queima na produção de calor e, consequentemente, a correta secagem dos grãos. A visão empreendedora utilizou uma técnica que consiste na promoção da sustentabilidade e a manutenção da qualidade do café, funcionando da seguinte forma: os queimadores são alimentados com os resíduos da palha do café para produção do calor e, os quais promovem a secagem dos grãos. Essa inovação tecnológica reduz a emissão de poluentes no ar.

Destarte, percebe-se que a técnica inovadora inviabiliza a utilização da madeira. Outrora a madeira era a matéria prima na secagem dos grãos de café, e o uso da nova técnica evita o desmatamento e a erosão do solo.

\section{Aspectos da Reserva Biológica Córrego do Veado}

$\mathrm{Na}$ oportunidade da visita à Reserva Biológica Córrego do Veado (Rebio), refletiu-se sobre os aspectos ambientais sobre uma visão introspectiva, relata-se que: 
A Reserva Biológica Córrego do Veado é uma instância federal do grupo de proteção integral e está sob a Jurisdição Legal de Domínio Mata Atlântica localizada no município de Pinheiros, norte do Espírito Santo, foi criada em 1948 como Reserva Florestal e assumiu a categoria de Rebio no ano de 1982 (UNIDADES DE CONSERVAÇÃO NO BRASIL, 2020).

O objetivo de criação da Rebio foi a preservação de tipos florísticos e fitofisionômicos da região norte que é caracterizada pela Mata Atlântica. A Rebio apresentava grande diversidade de espécies animais ameaçadas de extinção como a preguiça-de-coleira, o gavião-real, a cotinga, o macuco e alguns raros beija-flores. O clima da região tem fortes características da Serra. Neste sentido, a Rebio desenvolve ações de educação ambiental e possui um centro de vivência com animais, auditório e trilha para visitação da flora e da fauna (UNIDADES DE CONSERVAÇÃO NO BRASIL, 2020). Observou-se na oportunidade que está aberta para pesquisadores e visitação pública, percebeu-se ainda que a floresta enfrenta problemas antigos, como: caça à animais silvestres em ameaça de extinção e seca na região.

$\mathrm{Na}$ visão de pesquisadores atuantes na referida floresta, há fortes indícios que a seca instaurada na região norte do Estado do Espírito Santo não se trata de uma seca periódica, mas sim definitiva, pois nem em casos de chuvas intensas a bacia possui condições de armazenar água suficiente, devido ao estágio avançado de degradação da área. Além disso, a sub-bacia do Córrego Santo Antônio, que alimenta a Rebio Córrego do Veado, foi classificada em situação trágica. Os pesquisadores apontaram que os proprietários de terras na região se dedicam à criação de gado, plantio de café e eucalipto.

A floresta encontra-se em situação estável de conservação com trechos em recuperação e trechos bem conversados, todavia a regeneração desses trechos pode se tornar mais lenta e as mudanças climáticas podem acelerar a degradação da floresta. Algumas espécies da biodiversidade desapareceram e outras diminuíram, muitas delas possuem riscos de extinção, mas ainda tem potencial para a descoberta de espécies novas. Apesar de o veado ter desaparecido da área, ainda há a presença de populações de grandes herbívoros, mas estão sofrendo com o pequeno tamanho e com o isolamento da Reserva e estão ameaçadas à perda de espécies acarretada pela diminuição de qualidade ambiental. A água é o recurso mais crítico da Reserva, pois depende do entorno e enfrenta escassez, sendo a sua demanda desequilibrada e injusta (ICMBIO, 2019).

Em um todo, nota-se que a reserva está ameaçada por incêndios, caça, contaminação da água e do solo pelo uso de agrotóxicos no entorno com a reserva, ataque da fauna por cachorros domésticos, necessitando principalmente de planos de estudo e pesquisa, de proteção, de sensibilização ambiental e de responsabilidade da gestão da água (ICMBIO, 2019). 
A consequência das práticas citadas acima poderá resultar na extinção de algumas espécies de plantas e animais da floresta, colaborando com a indisponibilidade de um direito até então disponível perante a Constituição da República Federativa do Brasil.

\section{Considerações Finais}

O presente estudo demonstrou que a responsabilidade dos fomentadores da sustentabilidade no município de Pinheiros, na região norte do estado do Espírito Santo, diverge em relação à proteção integral do poder Público Federal. Verificou-se que a Reserva Biológica não possui a efetiva proteção legal do poder público federal, no entanto, as figuras da Associação ASCAP e de uma empresa produtora e exportadora de café demostraram compromisso socioambiental na execução da promoção do bem-estar social e ambiental.

Diante do já exposto, deduz-se que, na teoria, a União garante à Reserva Biológica Córrego do Veado proteção integral até o presente, no entanto, na prática a situação é contrária ao se perceber a hipossuficiência da fauna e da flora em relação ao ente federativo que de forma discricionária disponibiliza o bem tutelado e indisponível, o direito à vida.

\section{Referências}

ANTUNES, P. de B. Direito Ambiental. 19. Ed. São Paulo: Atlas, 2017.

AGRIZZI, A. P.; TEIXEIRA, M. da C.; SALUSTIANO, I. V.; RODRIGUES, L. A.; ALMEIDA, A. A.; PRAZERES, J. L. dos; BRITTO, I. O.; TEIXEIRA, R. M.; LEITE, J. P. V. Projeto Saberes da Mata Atlântica: Percepção ambiental e científica de estudantes do entorno do Parque Estadual da Serra do Brigadeiro (MG). Revista Brasileira de Educação Ambiental, v. 15, n. 7, p. 277-296, 2020.

BRASIL. Constituição (1988). Constituição da República. Senado Federal. Brasília. $1988 . \quad$ Disponível Em: <http://www.planalto.gov.br/ccivil 03/constituicao/constituicaocompilado.htm>. Acesso em: 02 ago. 2017.

BRASIL. Lei n. 12.305, de 2 de agosto de 2010. Institui a Política Nacional de Resíduos Sólidos; altera a Lei no 9.605, de 12 de fevereiro de 1998; e dá outras providências. Disponível em: $<$ http://www.planalto.gov.br/ccivil 03/ ato2007-2010/2010/lei//12305.htm>. Acesso em: 21 jun. 2020. 
BRASIL. Lei n. 6.938, de 31 de agosto de 1981. Dispõe sobre a Política Nacional do Meio Ambiente, seus fins e mecanismos de formulação e aplicação, e dá outras providências. Disponível em: $<$ http://www.planalto.gov.br/ccivil 03/LEIS/L6938.htm>. Acesso em: 21 jun. 2020.

BRASIL. Lei n. 9.795, 27 de abril de 1999. Dispõe sobre a educação ambiental, institui a Política Nacional de Educação Ambiental e dá outras providências. Diário Oficial da União. Brasília. Distrito Federal. DF, 28 abril. 1999. Disponível em: <http://www.planalto.gov.br/ccivil 03/leis/L9795.htm>. Acesso em: 27 jul. 2017.

BRASIL. Ministério do Meio Ambiente. Sistema Nacional do Meio Ambiente. Disponível em: <https://www.mma.gov.br/governancaambiental/sistema-nacional-do-meio-ambiente>. Acesso em: 25 jul. 2017.

ICMBio (Instituto Chico Mendes de Conservação da Biodiversidade). Plano de Manejo da Reserva Biológica do Córrego do Veado. 2019. Disponível em: $<$ https://www.icmbio.gov.br/portal/images/stories/docs-planos-demanejo/plano de manejo da rebio do corrego do veado.pdf>. Acesso em: 10 jan. 2021.

MINISTÉRIO PÚBLICO DO ESTADO DO ESPÍRITO SANTO. Termo de Compromisso Ambiental - TCA no 01/2013 - MPE/MPT/Município de Pinheiros. Disponível em: <http://pinheiros4.tempsite.ws/pinheiros/wpcontent/uploads/2013/10/18071000.pdf >. Acesso em: 02 ago. 2017.

RECEITA FEDERAL. Emissão de Comprovante de Inscrição e de Situação Cadastral. Disponível em: $<$ http://servicos.receita.fazenda.gov.br/Servicos/cnpjreva/Cnpjreva Solicitacao. asp>. Acesso em: 02 ago. 2017.

OLIVEIRA, A. N. de; DOMINGOS, F. de O.; COLASANTE, T. Reflexões sobre as práticas de Educação Ambiental em espaços de educação formal, nãoformal e informal. Revista Brasileira De Educação Ambiental, v.15, n.7, p.919, 2020.

UNIDADES DE CONSERVAÇÃO NO BRASIL. Reserva Biológica Córrego do Veado. Disponível em: <https://uc.socioambiental.org/uc/585564>. Acesso em: 10 jan. 2021. 